\section{Conclusions}

Whereas many studies have revealed the association of personality disorders with substance misuse, this study has highlighted the co-occurrence of specific maladaptive personality schemas with substance misuse. To improve the overall prognosis, these schemas can be addressed through specific cognitive-behavioural therapies such as the manualised treatment approach of dual-focus schema therapy (Ball, 1998).

\section{References}

Adamson, T. A., Onifade, P. O. \& Ogunwale, A. (2010) Trends in sociodemographic and drug abuse variables in patients with alcohol and drug use disorders in a Nigerian treatment facility. West African Journal of Medicine, 29, 12-18.

Ball, S. A. (1998) Manualised treatment for substance abusers with personality disorders: dual focus schema therapy. Addictive Behaviors, 23, 883-891.

Butcher, J. N., Graham, J. R., Ben-Porath, Y. S., et al (2001) MMPI-2 Manual for Administration, Scoring and Interpretation. University of Minnesota Press.
Craig, R. J. (1984) A comparison of MMPI profiles of heroin addicts based on multiple methods of classification. Journal of Personality Assessment, 48, 115-120.

Graham, R. J. (1993) MMPI-2: Assessing Personality and Psychopathology (2nd edn). Oxford University Press.

Makanjuola, J. D. A. (1986) The Aro drug addiction research and treatment centre: a first report. British Journal of Addiction, 81, 809-814.

National Institute on Drug Abuse (1999) Principles of Drug Addiction Treatment: A Research-Based Guide (2nd edn). NIH Publication No. 99-4180. Available at http://www.drugabuse.gov/PDF/PODAT/PODAT. pdf (accessed May 2010).

Steffenhagen, R. A. (1980) Self-esteem theory of drug abuse. In Theories on Drug Abuse: Selected Contemporary Perspectives (eds D. J. Lettieri, M. Sayers \& H. W. Pearson), pp. 96-95. National Institute on Drug Abuse. Available at http://archives.drugabuse.gov/pdf/monographs/30. pdf (accessed May 2010).

United Nations International Drug Control Programme (1998) Report of the Rapid Situation Assessment of Drug Abuse in Nigeria. UNDCP.

Verheul, R. (2001) Co-morbidity of personality disorders in individuals with substance use disorders. European Psychiatry, 16, 274-282.

World Health Organization (1992) International Classification of Diseases (10th revision) (ICD-10). WHO.

\title{
Public mental health services in Mumbai
}

\section{Ajanta Akhuly ${ }^{1}$ and Mrinmoyi Kulkarni ${ }^{2}$}

'Doctoral Research Scholar, Department of Humanities and Social Sciences, Indian Institute of Technology Bombay, Mumbai 400076, India, email ajanta@hss.iitb.ac.in; ${ }^{2}$ Assistant Professor, Department of Humanities and Social Sciences, Indian Institute of Technology Bombay

M umbai, India's largest city, also has the distinction of being the most populous city in the world. The association between urbanisation and mental illness has been widely documented (Harpham \& Blue, 1995, especially pp. 41-60). Mumbai is characterised by dense slums housing large migrant populations facing stressful lives. The state of publicly funded mental health facilities in Mumbai has special significance in this context, since they are the only resource available to a large economically vulnerable section of the population. The objective of the present study was to evaluate the public mental health services in Mumbai and to identify areas for improvement.

Mental disorders account for $8.5 \%$ of the national burden of disease in India (Peters et al, 2001). Statistics specific to Mumbai are not readily available but, given that $54 \%$ of the city's population of approximately 13 million live in slums, one can assume that this burden would be substantial.

\section{Public healthcare in Mumbai}

The Municipal Corporation of Greater Mumbai (MCGM) and the Maharashtra state government are the two independent bodies responsible for healthcare in Mumbai. The MCGM administers primary care through 185 municipal dispensaries and 176 health posts for out-patient services and public health activities, secondary care through 16 'peripheral' municipal general hospitals and 26 maternity homes in the surburbs, and tertiary care at three teaching hospitals. The state government runs one teaching hospital, three general hospitals and two health units (Dilip \& Duggal, 2004). Only ten of these hospitals have general hospital psychiatric units (GHPUs), which constitute the public mental health facilities for the city.

\section{Method}

The present study assessed nine of these ten GHPUs using the World Health Organization Assessment Instrument for Mental Health Systems (WHO-AIMS) version 2.2 (World Health Organization, 2005). This is a tool for collecting information on the mental health system of a country or region in order to identify weaknesses and make changes. Of the tool's six domains, numbers 2 (mental health services) and 4 (human resources) were adapted (based on a pilot study) for the current study by focusing on questions relevant to GHPUs.

Permission to conduct the study was obtained from the executive health officer of the MCGM. As aggregate data regarding mental health services are not maintained by the municipal public health department, data (hospital records, doctors' records and interviews with doctors) were obtained directly from nine of the GHPUs (one GHPU did not grant permission). Some of the data in the study were taken from doctors' records as opposed to official hospital records and there may be minor inconsistencies between the two, which do not, however, affect the overall trends presented here. 
Table 1 Number of psychiatric beds, patient load in out-patient department and human resources

$\begin{array}{lrrrrrrrrr} & \text { G1 } & \text { G2 } & \text { T1 } & \text { T2 } & \text { T3 } & \text { P1 } & \text { P2 } & \text { P3 } & \text { P4 } \\ \text { Number of beds } & 30 & 30 & 60 & 90 & 30 & 33 & \text { NA } & 25 & \text { NA } \\ \text { Number of patients per day in department } & 150 & 30 & 120 & 175 & 145 & 168 & 38 & 37 & 32 \\ \text { Number of doctors } & 5 & 1 & 4 & 5 & 3 & 6 & 2 & 3 \\ \text { Number of residents } & 6 & 2 & 4 & 8 & 8 & 0 & 0 & 4 \\ \text { Clinical psychologists } & 0 & 0 & 3 & 2 & 1 & 1 & 0 & 1 & 0 \\ \text { Social workers } & 1 & 0 & 2 & 3 & 2 & 1 & 1 \\ \text { Catchment area (ward population) } & & & & & & 2501000 & 1875377 & 2905047 & 1242000\end{array}$

G, state government hospitals; T, teaching hospitals; P, peripheral hospitals. NA, not applicable.

\section{Results}

Psychiatric in-patient units existed in only seven of the ten GHPUs. A total of 298 beds were recorded in these seven GHPUs, which was consistent with previous findings (Joshi, 2005) (see Table 1 for data from individual hospitals). In most cases, a family member was required to stay with in-patients to guard against suicide attempts as well as to prevent abandonment of the patient at the hospital by the family.

All ten hospitals had an out-patient department (OPD). The average total number of patients seen per day ranged from 30 to 175 , with the number of new patients ranging from 4 to 25 , the remainder being follow-up cases (Table 1). These numbers are consistent with a previous report (Joshi, 2005). The hospitals do not have formal catchment areas; however, the city is divided into wards (administrative zones) and people in all probability decide to go to the nearest peripheral hospital, hence we have reported in Table 1 the population of the ward where the hospital was located combined with that of neighbouring wards without hospitals.

Approximately $60 \%$ of the patients came to the GHPU without a referral from a general practitioner.

Four of the ten hospitals had a separate day on which children were seen in the OPD. One of the teaching hospitals had a special section for children, which included a centre for intellectual disabilities and a school for children with autism.

The teaching hospitals were relatively well staffed, with four doctors and six residents on average. Overall, the government and peripheral hospitals had fewer doctors, 2.2 on average, as well as fewer residents (1.5) (Table 1). The number of patients per doctor varied from 12 to 38 per day. Scanning facilities (magnetic resonance imaging or computerised tomography) were available in only five of the GHPUs.

Drugs were found to be the first line of treatment in all hospitals. Those listed in the National Therapeutic Drug policy, which include older-generation antipsychotics, mood stabilisers and anti-epileptics, are provided free to all patients, but patients are expected to buy drugs not on this list. Electroconvulsive therapy (ECT) was used in all the in-patient units but rarely in the OPD. In most cases, it was used only for suicidal ideation and schizophrenia. The Indian Psychiatric Society (IPS) considers ECT with anaesthesia a reasonable therapeutic modality (Addlakha, 2008, pp. 300-302).

Only four of the nine hospitals used some form of psychotherapy; cognitive-behavioural therapy was the most common, while others included behaviour therapy with relaxation, rational emotive therapy, couples and family therapy, biofeedback techniques for phobias and play therapy for children. In a fifth hospital a form of meditation (Vipashna) was used. However, in-patients were largely the recipients of therapy rather than out-patients and therapy sessions were always conducted by psychiatrists.

Interviews with 19 doctors revealed two major areas of concern: excessive patient loads, and additional administrative and organisational responsibilities. Areas for improvement suggested by doctors included the availability of both medicines (seven doctors) and digital electroencephalography (four doctors) and more psychologists and nursing staff (four doctors).

\section{Discussion}

The entire Mumbai mental health system is overburdened, partly because of the large numbers accessing mental healthcare without first consulting a primary care provider. The teaching hospitals were superior in terms of services offered, human resources and infrastructure, and were better funded than peripheral hospitals, by a factor of 10 (Verma, 2006). The peripheral hospitals in comparison with the teaching hospitals were lacking in terms of having a children's OPD (three of the four peripheral hospitals did not have one), clinical psychologists (two did not have one), scanning facilities (three did not have any) and the availability of medicines. These four peripheral hospitals together serve a population of around 8.5 million (Table 1).

It seems clear that upgrading the existing infrastructure of peripheral hospitals would lead to dramatic improvements in services provided, in terms of quality as well as accessibility. For the teaching and government hospitals it would not be possible to estimate the population served, for in addition to the population of the whole city they also serve the nearby districts, as well the state and the country in a nominal sense.

Around $60 \%$ of the patients came without a referral from primary care. This underscores the need to link mental healthcare to primary healthcare and develop a protocol for referrals at the primary care level. Since common mental disorders (CMDs) account for a large share of the disorders observed (as also confirmed by the current findings), it would be useful to train doctors at the primary level to manage CMDs in coordination with psychiatrists at the GHPUs (Sriram et al, 1990). The incidence of postpartum depression and its costs (Patel et al, 2004) is another urgent reason to link mental healthcare to primary care.

Psychotherapy was available to only a small group of patients and was under-utilised by the system. We feel its value needs to be systematically explored within the Mumbai mental health system, although this was not echoed by the doctors. Psychological counselling and therapy were reported as being the most well-received services after a restructuring 
of the health system in Shanghai (Yan, 1998). In Mumbai, it would be useful to document the role of psychotherapy for anxiety disorders (Roffman et al, 2005) and group psychotherapy for depression (Siskind et al, 2008), especially with reference to their cost-effectiveness. Developing a standardised psychotherapeutic model that has been adapted to the cultural milieu may help to make therapy more accessible to both patients and doctors. Another issue, also mentioned by Patel \& Kleinman (2003), is the difficult life circumstances faced by people on low incomes and the need for social interventions. Supportive counselling provided by psychologists and social workers for patients and family members also needs to be considered.

At a broader level, the absence of a detailed mental health plan (such as the Mental Health National Services Framework in the UK) and an executive body (such as the Division of Mental Hygiene Services in New York, USA) makes it impossible to plan for the city's mental health needs or to implement city-wide mental health education/awareness programmes. In this context, it would be useful if epidemiological data for mental health were maintained in a centralised manner, as this would facilitate research.

Finally, given the large numbers served by the system, even a partial implementation of these suggestions may result in significant improvements for a very large patient population. Given the extenuating life circumstances of patients, access to some treatment may allow people to live productive and relatively happy lives.

\section{Acknowledgements}

We would like to acknowledge the Executive Health Officer of the Municipal Corporation of Greater Mumbai and Dr Nilesh Shah.

\section{References}

Addlakha, R. (2008) Deconstructing Mental Illness - An Ethnography of Psychiatry, Women and the Family. Zubaan.

Dilip, T. R. \& Duggal, R. (2004) Unmet need for public healthcare services in Mumbai, India. Asia-Pacific Population Journal, 19, 27-39.

Harpham, T. \& Blue, I. (eds) (1995) Urbanisation and Mental Health in Developing Countries. Ashgate.

Joshi, A. (2005) Mental health in India: review of current trends and directions for the future. In Review of Health Care in India (eds L. V. Gangolli, R. Duggal \& A. Shukla), pp. 127-136. CEHAT.

Patel, V. \& Kleinman, A. (2003). Poverty and common mental disorders in developing countries. Bulletin of the World Health Organization, 81, 609-615.

Patel, V., Rahman, A., Jacob, K. S., et al (2004) Effect of maternal mental health on infant growth in low income countries: new evidence from South Asia. BMJ, 328, 820-823.

Peters, D., Yazbeck, A., Ramana, G., et al (2001) Raising the Sights: Better Health Systems for India's Poor. World Bank.

Roffman, J. L., Marci, C. D., Glick, D. M., et al (2005) Neuroimaging and the functional neuroanatomy of psychotherapy. Psychological Medicine, 35, 1385-1398.

Siskind, D., Baingana, F. \& Kim, J. (2008) Cost-effectiveness of treatments for depression in Uganda. Journal of Mental Health Policy and Economics, 11, 127-133.

Sriram, T. G., Moily, S. \& Kumar, G. S. (1990) The training of primary health care medical officers in mental health care: errors in clinical judgement before and after training. General Hospital Psychiatry, 12, 384-389.

Verma, M. (2006) Recommended Policy Guidelines for Public Health. Draft dated 1st May, 2006 for discussion. A Report to the MCGM and the NGO Council. Available at http://www.karmayog.com/ publichealth/publichealthindex.htm (accessed 26 November 2009).

World Health Organization (2005) WHO-AIMS. World Health Organization Assessment Instrument for Mental Health Systems, version 2.2. Available at http://www.who.int/mental health/evidence/AIMS WHO 2_2.pdf (accessed August 2010).

Yan, H. Q. (1998) New challenges of psychiatry: the development of mental health services in Shanghai. Psychiatry and Clinical Neurosciences, 52, 357-358.

\title{
UK devolution and the international perspective of the College
}

\author{
Nick Craddock
}

Department of Psychological Medicine and Neurology, School of Medicine, Cardiff University, UK, email craddockn@cardiff.ac.uk

\begin{abstract}
Come principles of psychiatric practice are applicable across all healthcare settings and epochs, whereas other issues are more specific to one healthcare model and/or time. The increasing divergence of service models and underlying policies in the four UK devolved jurisdictions (England, Northern Ireland, Scotland and Wales) means that this distinction between general and specific issues has increasing relevance to the College. There are many benefits in identifying, and being strong advocates for, the generic principles of excellent psychiatric care, which are transferable across settings and relatively stable over time. These are also, of course, the principles that will have the most relevance in a broad international perspective that goes far beyond the UK.
\end{abstract}

The role of the psychiatrist in healthcare inevitably varies over time and place, according to the specific service model, statutory legal framework, needs of the population served and the number and skill mix of other professionals. It is unrealistic (and probably undesirable) to think there should or could ever be a 'one size fits all' service model for how psychiatrists use their skills optimally to benefit patients. This applies at all levels of service variation. Perhaps most obviously, major differences occur between different areas of the world, as geographical and cultural context (e.g. Sorketti et al, 2010) as well as economic constraints (e.g. Muijen, 2010) exert profound influences. However, although the variations may be within a much more moderated range, there are increasingly important differences within the UK. The four 